\title{
A Turn-Taking Analysis of the Characters' Personalities and Relationships in Thelma \& Louise
}

\author{
Haixia Yang \\ School of Foreign Languages, North China Electric Power University, Changping District, Beijing, China \\ Yuetian $\mathrm{Lu}$ \\ School of Foreign Languages, North China Electric Power University, Changping District, Beijing, China
}

\begin{abstract}
Thelma \& Louise, directed by Ridley Scott, is regarded as a masterpiece of American feminism films. The film involves gender inequality, morality and violence, and challenges people's thoughts in a patriarchal society. It finds that using turn-taking framework can help us better understand the characterization and its relationship in the film, but also enable readers to make comments on the characters on a relatively objective basis. It brings a new angle to the analysis of movie text, which helps people to observe the characters' characteristics and understand the relationship among the characters.
\end{abstract}

Index Terms - turn-taking, Thelma \& Louise, feminism, growth, rebellion

\section{INTRODUCTION}

Based on the current theory of conversational analysis, this paper analyzes the turn-takings in the film Thelma \& Louise and tries to explore the personalities of the main characters in the film and the relationships between them, as is revealed in the dialogue. This chapter will briefly introduce Thelma \& Louise and the turn-taking theory.

\section{A. Introduction of Thelma \& Louise}

Thelma \& Louise (1991) is a representative feminist movie to fight against the patriarchal society. Thelma and Louise were close friends. Thelma was a docile, timid housewife, having an emotionally abusive husband, while Louise was an ordinary looking, manly waitress in the restaurant. They planned to drive for a holiday, and it was supposed to be a simple and pleasant journey. However, it became a struggle of two women against the oppression of male society.

In a bar, a man accosted Thelma. In the beginning, they were just flirting, but the man later attempted to rape her. In a hurry, Louise rushed to shoot the man to death. Assuming the police would not believe their self-defense motive, they ran away.

Finally, they drove down the Grand Canyon and killed themselves. On their journey, they fought back against men and injustice, and they changed and grew up. All events and conversations in the movie are symbols of men status and social phenomena at that time.

\section{B. Introduction of Turn-Taking}

Conversation analysis, an important branch of pragmatics, aims to reveal the basic structural features of conversations, and analyze the linguistic performance in social activities. The core theory of conversation analysis, turn-taking, was first put forward by Harvey Sacks, Emanuel A. Schegloff and Gail Jefferson in 1974. At that time, turn-taking was mainly used to study daily conversations. Later, with the development of drama semiotic, turn-taking has been introduced into the script analysis as a particular way to analyze dialogue. The framework provides a new method for the study of film texts, and it can well reveal characters' personality and power relationships in the film.

A turn is a time during which a single participant speaks, with typical, orderly arrangement in which participants speak with minimal overlap and gap between them (Levinson, 2001). And Li Yuee and Fan Hongya (1998) viewed that "a turn is speaker's continuous sayings in any time in the process of conversation and the end of a turn is marked by change of role between speaker and listener or one side's silence or yielding of turn" (p. 29). For the convenience of quantitative analysis, this paper regards every utterance in the film as a turn ( $\mathrm{Li} \& \mathrm{Yu}, 2001, \mathrm{p}$. 26). According to the actual needs, this paper adopts the quantitative analysis framework of turn-taking used by Li Huadong and Yu Dongming in drama stylistics, including the initiation and control of topics, turn length, turn type, interruption and monologue, and turn control strategies (Liu \& Zhu, 2006), and the turn-taking model put forward by Wang Hong (2006) in Drama Stylistic Analysis: Discourse Analysis Method. Combined with the language of this movie, some changes are made to this framework. 
From the perspective of turn-taking, this part, selecting eight representative conversations between two pairs of characters in the film, systematically quantifies the discourse characteristics of the protagonists Thelma and Louise. By doing so, it shows the inner changes of the protagonist Thelma from their discourse changes, so as to reveal how Thelma grows up from a naive little girl to a woman with self-protection ability and independent personality, and how her transformation promotes the development of movie plot.

\section{A. Conversations between Thelma and Louise}

The following conversation is extracted from the beginning of the movie. Louise calls Thelma and asks if she prepares for their trip (see Table 1).

TABLE 1

STATISTICAL RESULT OF EXCERPT 1

\begin{tabular}{|c|c|c|c|}
\hline \multicolumn{2}{|c|}{ Characters } & Louise & Thelma \\
\hline \multicolumn{2}{|c|}{ Number of turns } & 3 & 4 \\
\hline \multicolumn{2}{|c|}{ Initiation \& Topic-Control } & More control & Less control \\
\hline \multicolumn{2}{|c|}{ Average Length of Turns (words) } & 21 & 8 \\
\hline \multirow{3}{*}{ Turn-type } & Initiation & 1 & 1 \\
\hline & Response & 1 & 3 \\
\hline & I after $\mathrm{R}$ & 1 & 1 \\
\hline
\end{tabular}

In this clip, after Thelma answers the phone and greets, Louise starts a topic and asks Thelma how she prepares for the trip. Thelma follows the topic, saying that she needs to discuss it with her husband. Louise then launches on this topic, criticizing Thelma. Thelma thinks her husband would not agree. After two turns, the call is over.

In this dialogue, Louise has 3 turns, both of which are initiation, one is response to Thelma's questions, and the average length of turns is 21 words; Thelma does not really initiate a topic, and the average length of turns is 7.3. Obviously, Louise dominates the call and controls the right to speak. Thelma just passively accepts Louise's domination. In the phone call, she says that she needs to ask her husband's permission to go out for a trip. It shows that Thelma is a full-time housewife who has never left her home alone. In her family, she also passively accepts her husband's domination. She has no initiative.

The following conversation happens when Louise and Thelma escape the murder scene and discuss countermeasures (see Table 2).

TABLE 2

STATISTICAL RESULT OF EXCERPT 2

\begin{tabular}{|c|c|c|c|}
\hline \multicolumn{2}{|c|}{ Characters } & Louise & Thelma \\
\hline \multicolumn{2}{|c|}{ Number of turns } & 7 & 8 \\
\hline \multicolumn{2}{|c|}{ Initiation \& Topic-Control } & More control & Less control \\
\hline \multicolumn{2}{|c|}{ Average Length of Turns (words) } & 22.3 & 9.7 \\
\hline \multirow{3}{*}{ Turn-type } & Initiation & 2 & 6 \\
\hline & Response & 4 & 3 \\
\hline & I after $\mathrm{R}$ & 6 & 1 \\
\hline
\end{tabular}

After Louise shoots the man who attempts to rape Thelma, they quickly flee the scene and discuss countermeasures. This scene is the beginning of their escape. In this clip, Thelma starts the conversation to ask what to do next. Louise gives a negative answer and asks her to be quite so that she can calm down and think of a solution. Thelma, on the other hand, starts another conversation, suggesting that they should call the police immediately. Louise asks questions and makes her own judgment. Thelma agrees and shifts the topic to talk about her feelings about the trip, while Louise refutes this new topic.

There are 15 turns in total in this conversation, of which Thelma has 8 turns and Louise has 7 turns, which are basically the same. In terms of turn types, Thelma initiates topics six times, while Louise rarely does. On the surface, Thelma seems to have control and dominant position, but it is easy to find that her words are all in the form of questions, asking Louise what to do next. This reflects that Thelma does not know where to go, so she has to start a conversation and ask Louise for help. Although Louise does not initiate a topic, every turn of her talk is an initiation after response. She analyzes and answers Thelma's questions and provides assistance to comfort the injured Thelma, which makes her average length of turn 22.3 words. Therefore, it is Louise who controls the right of speech in the real sense, which shows her strong, calm and self-confident side, and also reflects Thelma's characteristic of simplicity, indecision, panic, lack of social experience and immaturity of mind.

The following dialogue happens when Thelma and Louise find out their money is stolen (see Table 3). 
TABLE 3

STATISTICAL RESULT OF EXCERPT 3

\begin{tabular}{|c|c|c|c|}
\hline \multicolumn{2}{|c|}{ Characters } & Louise & Thelma \\
\hline \multicolumn{2}{|c|}{ Number of turns } & 1 & 2 \\
\hline \multicolumn{2}{|c|}{ Initiation \& Topic-Control } & Less control & More control \\
\hline \multicolumn{2}{|c|}{ Average Length of Turns (words) } & 44 & 49.5 \\
\hline \multirow{3}{*}{ Turn-type } & Initiation & 1 & 2 \\
\hline & Response & 1 & 0 \\
\hline & I after $\mathrm{R}$ & 0 & 0 \\
\hline
\end{tabular}

Louise gets money from her boyfriend and leaves it in Thelma's custody. Unexpectedly, her money has been stolen by the thief J. D. In this clip, Thelma starts the topic first. She expresses her anger at J. D. for stealing money in an unprecedented tone. Louise then follows the topic, expressing the seriousness of the problem of losing money and confusion about their future.

In this segment, Thelma and Louise's power relationship and character are all revealed. There are 3 turns in this clip, of which Thelma initiates the topic and takes two turns, 9 words in total, while Louise only has 1 turn. It is clear that Thelma is in control of the right to speak at this moment. Moreover, nearly half of Thelma's words are imperative sentences, and she uses the tone of command to comfort Louise. Louise, on the other hand, expresses her confusion about their future. After losing money, Louise is in despair, almost collapsed and has no idea. Under the paralinguistic feature, she is squatting in the ground and crying helplessly. But Thelma is totally changed. Obviously, the little girl who was scared, dazed and coquettish, suddenly becomes mature. It is from this moment that Thelma begins to be strong.

The next clip starts with Thelma pointing her gun at the traffic police and ends with Thelma and Louise locking him in the trunk and driving away (see Table 4).

TABLE 4

STATISTICAL RESULT OF EXCERPT 4

\begin{tabular}{|c|c|c|c|c|}
\hline \multicolumn{2}{|c|}{ Characters } & Louise & Thelma & Policeman \\
\hline \multicolumn{2}{|c|}{ Number of turns } & 9 & 10 & 1 \\
\hline \multicolumn{2}{|c|}{ Initiation \& Topic-Control } & Less control & More control & Losing control \\
\hline \multicolumn{2}{|c|}{ Average Length of Turns (words) } & 5.8 & 19.7 & 8 \\
\hline \multirow{3}{*}{ Turn-type } & Initiation & 2 & 7 & 1 \\
\hline & Response & 1 & 2 & 0 \\
\hline & I after R & 0 & 0 & 0 \\
\hline
\end{tabular}

There are 20 turns in this clip, including 10 for Thelma, 9 for Louise and 1 for the traffic police. Obviously, Thelma and Louise control the right of speech as well as the traffic police. In terms of the average length of turns, Thelma has an average length of 19.7; while Louise averages 5.8 words. From the perspective of turn-type, Thelma has 7 times of initiations, while Louise has only 2 times. Although the total number of turns of Louise is almost same as Thelma, most of them are responses to Thelma. Therefore, it can be seen from the data that Thelma has absolute discourse control right. It is showed that from this clip Thelma has changed her image from being nervous and at a loss in trouble, submissive to men, obedient to orders, and now becomes an independent woman with a strong sense of autonomy and resistance. Thelma's armed robbery store may be a little immature and lack of innovation, but this time, the hijack seems to be much more skillful.

The following clip starts with the truck driver parking and ends with Thelma and Louise driving away (see Table 5).

TABLE 5

STATISTICAL RESULT OF EXCERPT 5

\begin{tabular}{|c|c|c|c|c|}
\hline \multicolumn{2}{|c|}{ Characters } & Louise & Thelma & Truck driver \\
\hline \multicolumn{2}{|c|}{ Number of turns } & 11 & 10 & 11 \\
\hline \multicolumn{2}{|c|}{ Initiation \& Topic-Control } & Less control & More control & Losing control \\
\hline \multicolumn{2}{|c|}{ Average Length of Turns (words) } & 11.1 & 7.4 & 6.5 \\
\hline \multirow{3}{*}{ Turn-type } & Initiation & 8 & 6 & 3 \\
\hline & Response & 2 & 1 & 8 \\
\hline & I after $\mathrm{R}$ & 0 & 1 & 0 \\
\hline
\end{tabular}

In this clip, there are 32 turns in total, of which Thelma has 10, Louise has 11, the truck driver has 11, and the number of turns each character is basically the same. In terms of average length of turn, Thelma has an average length of 7.4 words per turn; Louis has 11.1 words per turn; and the truck driver 6.5 words. It's clear that Thelma and Louise dominate the conversation. This is more obvious from the perspective of turn type. Thelma or Louis is the initiator of every topic. The truck driver has never initiated a topic at one time. He is just following the topics of the two heroines, simply responding, repeating and cursing.

Compared with Thelma, Louise has the advantage of dominant discourse, because this time Louise first raised her gun. But compared with their paralinguistic features, Thelma pulls out the gun, shoots at the truck right away, and Louise threatens the driver for a long time, which shows Thelma's inner firmness. It can be said that the confrontation with the truck driver makes Thelma and Louise's image of strong woman to the top. Their consciousness and will of 
woman's rights has been highlighted unprecedentedly. They have become strong women fighters to defend their rights. After all kinds of experiences, with the help of Louise, Thelma finds herself for the first time as well as the opportunity to express her feelings. And it is this spirit that inspires them to march forward bravely, and indicates the arrival of the climax part.

This next excerpt begins when Louise realizes they have been seen by the police and finishes till the film's ending (see Table 6).

TABLE 6

STATISTICAL RESULT OF EXCERPT 6

\begin{tabular}{|c|c|c|c|}
\hline \multicolumn{2}{|l|}{ Characters } & Louise & Thelma \\
\hline \multicolumn{2}{|c|}{ Number of turns } & 17 & 17 \\
\hline \multicolumn{2}{|c|}{ Initiation \& Topic-Control } & Less control & More control \\
\hline \multicolumn{2}{|c|}{ Average Length of Turns (words) } & 6.2 & 6.6 \\
\hline \multirow{3}{*}{ Turn-type } & Initiation & 2 & 15 \\
\hline & Response & 13 & 2 \\
\hline & I after R & 1 & 0 \\
\hline
\end{tabular}

This clip has 34 turns, 17 for each of them. The average length of turn is 6.6 and 6.2 respectively. In terms of turn types, Thelma initiates topics 15 times in total, while Louise initiates topics 2 times. This shows that at the end of the film, Thelma has completely controlled the right to speak. What issues they are going to discuss and where they are going are all under Thelma's control. After the escape, Thelma, becoming a big woman who has a strong sense of autonomy and ideas, is indomitable and courageous.

\section{B. Conversations between Thelma and Her Husband Darryl}

This group of conversation happens after Louise's call at the beginning of the movie. It is the first time in the movie that Thelma talks to her husband (see Table 7).

TABLE 7

STATISTICAL RESULT OF EXCERPT 7

\begin{tabular}{|c|c|c|c|}
\hline \multicolumn{2}{|c|}{ Characters } & Thelma & Darryl \\
\hline \multicolumn{2}{|c|}{ Number of turns } & 7 & 7 \\
\hline \multicolumn{2}{|c|}{ Initiation \& Topic-Control } & Less control & More control \\
\hline \multicolumn{2}{|c|}{ Average Length of Turns (words) } & 8.7 & 9.7 \\
\hline \multirow{3}{*}{ Turn-type } & Initiation & 6 & 0 \\
\hline & Response & 1 & 5 \\
\hline & I after $\mathrm{R}$ & 1 & 2 \\
\hline
\end{tabular}

Thelma reminds Darryl to come to have breakfast quickly, while he says dirty words and tells Thelma not to shout loudly in the morning. Thelma twice wants to talk about the trip, but finally does not say it. Her husband replies impatiently, "what?" When she asks what to eat in the evening, Darryl mumbles at her again. Then Thelma wants to find some topics to ease the atmosphere, but he is still impatient.

They have the same number of turns. Thelma initiates topics six times in this conversation, but all of them are exploratory questions, while Darryl is responding to the topic impatiently. On the surface, Thelma has control and dominant position, but in fact, her husband has the dominant power of discourse. It can be seen that Thelma at this time is a housewife without status, and she completely obeys her husband.

However, in the following conversation, things change. This scene happens on their way to escape (see Table 8).

TABLE 8

STATISTICAL RESULT OF EXCERPT 8

\begin{tabular}{|c|c|c|c|}
\hline \multicolumn{2}{|c|}{ Characters } & Thelma & Darryl \\
\hline \multicolumn{2}{|c|}{ Number of turns } & 6 & 7 \\
\hline \multicolumn{2}{|c|}{ Initiation \& Topic-Control } & Less control to more control & More control to less control \\
\hline \multicolumn{2}{|c|}{ Average Length of Turns (words) } & 9.3 & 10.9 \\
\hline \multirow{3}{*}{ Turn-type } & Initiation & 3 & 5 \\
\hline & Response & 4 & 2 \\
\hline & I after $\mathrm{R}$ & 0 & 1 \\
\hline
\end{tabular}

Thelma and Louise left the hotel, and continue to flee. Thelma, who has not made up her mind to escape, calls home. In this clip, Darryl starts with a topic and directly asks where they are going. Thelma tells him where she is going. However, Darryl does not listen to her at all. He is furious, orders her to go home and criticizes Thelma for being crazy. Thelma, on the other hand, follows the topic closely and offers a further explanation. At this time, Darryl interrupts Thelma, because he wants to watch the football game on TV. Thelma finishes explaining, and Darryl does not care about it. Then Thelma refutes him for the first time, "you're my husband, not my father." But there is a more furious roar or the phone. Thelma says for the first time, "go fuck yourself!", then drops the phone and completely abandons her concern for the family. 
There are 13 rounds in this clip, including six for Thelma and seven for Daryl, which is basically the same. In the first half of the dialogue, Daryl always initiates the topic, and he initiates several interruptions. Obviously, he does not really care what his wife is doing or saying. Thelma just responds and explains. This reflects the unequal status of them in the family, that is, the husband is superior to his wife. Interestingly, the last six rounds of the clip are exactly the opposite of the first half. This time Thelma always initiates the topic, and her tone is firm, while her husband obviously loses his right to speak. This indicates the coming of great changes and the gradual growth of Thelma. From this point of view, this segment paves the way for the future development of the story, thus promoting the development of the whole story.

\section{Personalities of the Main Characters}

The above has analyzed eight groups of dialogues between the main characters and clarified the relationship between dialogues and characters. Since these dialogues are analyzed according to the sequence of plots, we can also infer some information about plot development and character shaping.

\section{A. Personality of Thelma}

Thelma is the key character in the film as well as the most obviously changed one. As Tables 1 and 7 show, Thelma is a housewife who obeys her husband's order before the trip. She has no life of her own. When Louise asks her to have a trip, she is still busy making breakfast for her husband. She even does not dare to mention this simple trip to her husband. She is a woman at the mercy of a patriarchal society. Therefore, Thelma, who just gets rid of her husband, is eager to go to the bar to have fun. In the bar, she is curious, naive and playful, which brings about the humiliation of Harlan. In addition, as shown in Table 2, when they start to escape, she is still at a loss. She just cries and asks Louise for her opinion. All of these show her trying to escape from problems and compromise with patriarchal society.

However, in the process of escape, she begins to change. As shown in Table 2, when she calls her husband, at the beginning, she is still explaining. After being yelled by her impatient husband, she finally hangs up decisively. As Table 3 shows, when she finds that the money for their life is a stolen by J. D. who she thinks to be a romantic lover, Thelma quickly wakes up and gets mature. She liberates and strengthens from the long repressed and bullied self, and encourages and comforts the desperate Louise. In the process of escape, she grabs the gun and bullet of the traffic police and ties him in the trunk; facing the ferocious tanker driver, she and Louise shoots the tanker and leave (see Table 4 and 5). At this time, Thelma is no longer the weak, helpless, independent little woman. After realizing the unfairness brought to women by the patriarchal society, her inner reason begins to wake up and pursue freedom and equality. As shown in Table 6, at the end of the movie, Thelma has full control of the topic. What they are going to discuss and where they are going are all under Thelma's control. Her last strong words, "let's keep going... Go!", shows her tenacity and determination. When they hold each other's hands and drive to the cliff, the movie reaches its climax. This shows that Thelma has gradually changed from a housewife who is at a loss when in trouble to a strong woman.

\section{B. Personality of Louise}

In most of the dialogues in the first half of the movie, Louise has more control over the topic and a longer average length of turn. In her first conversation with Thelma (see Table 1), Louise shows her frankness and independence. In this clip, it's clear that Louise controls the topic. In addition, she has a strong, calm and confident character. As Table 2 shows, after shooting the rogue, they discuss the countermeasures. In this clip, Louise firmly denies Thelma's unrealistic ideas and asks her to be quiet so that she can calm down and come up with a solution. She analyzes and answers Thelma's questions and helps.

However, as Table 3 shows, when the life-saving money is stolen, she is desperate and almost collapsed. She is at a loss and just squatted on the ground and cries helplessly. In short, it can be seen that Louise is a totally different woman from Thelma in character and experience. She is independent, capable and strong. Economically, psychologically and spiritually, she does not rely on men. She has a certain sense of autonomy from the beginning. However, since there is a secret in her heart that she has been insulted by men in Texas, she had a sense of distrust and estrangement towards men (He, 2013, p. 52). She is a woman of heartache and pity, not only because of her tragic experience, but also because of her sensitivity and tenacity to the injustice of patriarchal society.

\section{Relationships BETWEEN THE MAin CHARACTERS}

In this chapter, the relationship between the main characters will be analyzed according to the features of their conversations.

\section{A. Relationship between Thelma and Louise}

From the analysis of the dialogues between Thelma and Louise, we can see that at first Louise is the leader between them. She starts the journey, leads the conversation, teaches Thelma not to rely on her husband, and Thelma has always been hesitant. When the naive Thelma wants to revel in the bar, Louise always protects Thelma as a guardian and saves her in a critical moment. After the killing, Thelma keeps asking Louise for advice. She is totally dependent on Louise, who thinks calmly and figures out the escape route. It can be said that Thelma relies on Louise in the first half of the 
movie. Since the money is stolen, the status of the two changes. Louise has lost her fighting spirit and hope. Thelma has grown up rapidly, and encourages Louise. After that, Thelma robs cash to solve their economic problems, kidnaps the police to solve their security problems, and takes the lead in shooting oil tankers to give the unscrupulous driver a lesson. It can be seen that Thelma has completely become the leader of the relationship.

On the other hand, they support each other and comfort each other. They are each other's comrades in arms. Without Louise's teaching, protection, and demonstration, Thelma may always be a panicky, weak woman. Without Thelma's later consolation and decisive decision-making, they might have been caught by the police. The relationship between the two shows the friendship between females.

\section{B. Relationship between Thelma and Her Husband Darryl}

In their first conversation, Thelma's husband never calls her nickname, his words are vulgar, and he always responds negatively to Thelma. He always dominates the right of topic, and is the absolute master of the family. Thelma has no place in the family. In this family, men and women have different status and authority. Men dominate, while women are subordinate. There is no equal right.

However, after Thelma begins to flee, everything changes. When they are on the phone, at first Darryl is dominating Thelma, but when Thelma realizes that her husband does not respect her at all and is hopeless, she finally gives up her hope of returning to the family. She curses Darryl and hangs up. We can see clearly that Thelma is no longer under her husband's control after experiencing the harm of men and social injustice. She bravely challenges the authority of men and finally achieves self-liberation.

\section{CONCLUSION}

Thelma \& Louise is a representative feminist movie to fight against the patriarchal society. Their escape is a journey to find their true selves as well as a process of exposing the patriarchal society and male image. This mature process is accompanied by crime, bloodshed and sacrifice. They learn to resist in insult and oppression, and learn to be strong in resistance. By using the theory of turn-taking to analyze Thelma's discourse quantitatively, we can find more objective and quantitative evidences for her gradual growth.

The above analysis enables us to have a further understanding of the relationship and character of the characters in the film. It shows that the turn-taking mechanism is one of the effective ways to analyze the relationship between characters and their personalities in literary works.

\section{REFERENCES}

[1] He, Y. (2013). Fei xiang de zi tai dian ying mo lu kuang hua de nv xing zhu yi [The Posture of Flight-A Feminist Interpretation of Thelma \& Louise]. Zheng zhou hang kong gong ye guan li xue yuan xue bao, (3): 52-54.

[2] Levinson, S. C. (2001). Pragmatics. Beijing: Foreign Language Teaching and Research Press.

[3] Li, H. D. and Yu, D. (2001). Cong hua lun zhuan huan kan quan shi guan xi xing ge ke hua he qing jie fa zhan [Power Relations, Characterization, and Plot Development Revealed by a Turn-taking Analysis]. Jie fang jun wai guo yи хие yиan xue bao. (2): 26-30.

[4] Liu, S. S. and Zhu, R. Q. (2006). Wen ti xue gai lun [Introduction to Stylistics]. Beijing: Beijing U of P.

[5] Li, Y. E. and Fan, H. Y. (1998). Zhao hu yu yu yong shi wu fen xi ji ce lue [An Analysis of Inappropriate Greetings and the Strategies]. Foreign Languages and Their Teaching. (11): 29-32.

[6] Wang, H. (2006). Xi ju wen ti fen xi hu ayu fen xi de fang fa [Stylistic Analysis of Drama: a method of discourse analysis]. Shanghai: Foreign Language Education Press.

Haixia Yang was born in Jiyuan, China in 1976. She received her master's degree in linguistics from Sichuan International Studies University, China in 2001.

She is currently an associate professor in the School of Foreign Languages, North China Electric Power University, Beijing, China. Her research interests include linguistics and foreign language teaching.

Yuetian Lu was born in Weifang, China in 1998. She received her bachelor's degree from Ludong University, China in 2020. She is currently a graduate student for her master's degree at the School of Foreign Languages, North China Electric Power University, Beijing, China. Her research interests include British and American Literature. 